\title{
HEALTHY BEHAVIOURS, LIFESTYLE PATTERNS AND SOCIODEMOGRAPHIC DETERMINANTS OF THE METABOLIC SYNDROME
}

\author{
Magdalena Kwaśniewska', Dorota Kaleta', Elżbieta Dziankowska-Zaborszczyk ${ }^{1}$, Wojciech Drygas ${ }^{1,2}$ \\ ${ }^{1}$ Department of Social and Preventive Medicine, WHO Collaborating Centre for Noncommunicable Disease Prevention and Control, \\ Medical University of Łódź, Poland \\ 2Department of Epidemiology, Cardiovascular Prevention and Health Promotion, Institute of Cardiology, Warsaw, Poland
}

\section{SUMMARY}

Aim: The aim of this study was to examine the influence of healthy behaviours, lifestyle patterns and sociodemographic factors on risk of the metabolic syndrome (MS) in adult residents of rural, small town and large urban areas in Poland.

Material and methods: Cross-sectional analysis of randomly selected representative sample of 1,187 men and women aged 20-74 years participating in the nationwide health survey WOBASZ. Metabolic syndrome was defined by AHA/NCEP criteria (2005). Analysed healthy behaviours included nonsmoking, healthy weight, adequate fruits and vegetables consumption, regular leisure-time physical activity. The 4 lifestyle factors were summed to create a lifestyle index (range $0-4$ ).

Results: Regardless of gender healthy weight, adequate fruits and vegetables consumption and physical activity were associated with lower odds of MS. Non-smoking was significantly related to the lower odds ratio of MS only among men. Following all 4 lifestyle factors was the strongest protective factor against having MS. Being higher educated, in the 20-34 years old cohort, living in the rural area were the most important sociodemographic factors reducing risk of MS.

Conclusions: The obtained results support the need for effective promotion of healthy behaviors and lifestyle patterns, especially in demonstrated high-risk sub-populations. Due to important differences in metabolic risk between various sociodemographic groups, health promotion interventions should be specific in respect to the targeted subpopulations.

Key words: lifestyle, healthy behaviours, lifestyle index, metabolic syndrome

Address for correspondence: M. Kwaśniewska, Department of Social and Preventive Medicine, WHO Collaborating Centre for Noncommunicable Disease Prevention and Control, Medical University, ul. Zeligowskiego 7/9, 90-752 Łódź, Poland.

E-mail: magdalena.kwasniewska@unmed.lodz.pl.

\section{INTRODUCTION}

Lifestyle imposed by modern civilisation becomes more and more important factor influencing health state of most developed countries. Unhealthy behaviours are substantially responsible for epidemic prevalence and mortality of cardiovascular diseases, cancers, diabetes and respiratory disorders $(1,2)$. There is increasing body of evidence that following a healthy lifestyle including non-smoking, appropriate diet, satisfactory physical activity level and healthy weight can provide substantial cardiovascular and metabolic benefits $(3,4,5,6)$.

The metabolic syndrome (MS) is a cluster of risk factors that predisposes to increased risk of chronic noncommunicable diseases. According to the findings of $\mathrm{Hu}$ et al. persons with the MS have an increased risk of death from all causes as well as cardiovascular diseases (7).

Whereas much is known about the prevalence of single risk factors and their association with metabolic risk $(8,9,10,11)$, the literature on the relationship between multiple lifestyle-related factors and MS is scarce.

Increased understanding of the prevalence and patterns of healthy behaviours may improve planning new effective health promotion programmes and result in better overall health outcomes. Therefore, we decided to estimate the risk of metabolic syndrome in the context of lifestyle characteristics and sociodemographic factors which may predict adherence to these factors in a representative sample of Polish adults.

\section{MATERIAL AND METHODS}

The subject population was derived from the Multi-Center All-Polish Health Survey - the nationwide representative study WOBASZ conducted in the years 2002-2005 (12).

For the purpose of the present analysis the sample consists of randomly selected adult residents of two Polish counties (Lodz and Lublin voivodeships). The sampling schema was two step stratification: first, selection of 7 areas in each county ( 2 rural areas i.e. $\leq 8,000$ inhabitants; 2 small town areas, i.e. 8,000-40,000 inhabitants; 2 large town areas, i.e. $>40,000$ inhabitants; and 1 capital city of the county) and second, selection of samples including 100 women and 100 men aged 20-74 years in each area.

A total of 2,800 personal invitations to participate in the study were sent by mail. With the mean response rate $88.4 \%$, the study 
enrolled 2,474 individuals. The whole panel of the study procedures (including data on dietary habits) was carried out in the $50 \%$ randomly selected sub-sample of the whole population. Due to missing data related to several variables of interest, analyses were conducted on data obtained from 1,187 persons aged 20-74 years, 624 (52.6\%) women and $563(47.4 \%)$ men.

The investigation procedures took place in selected out-patient clinics and consisted of a detailed questionnaire interview, measurements of blood pressure, height, weight and waist circumference, and a fasting blood sample collection. The questionnaire used in this project was elaborated by main investigators of the WOBASZ Study. Most of questions (including eating habits and physical activity level) were based on internationally used standardized methods. All the procedures were performed by trained interviewers and nurses. Detailed methodology of the WOBASZ project has already been published in previous reports (13).

According to the AHA/NHLBI (2005) criteria the metabolic syndrome was diagnosed in individuals with at least 3 of the following metabolic risk factors: abdominal obesity (waist circumference $\geq 88 \mathrm{~cm}$ in women and $\geq 102 \mathrm{~cm}$ in men), elevated blood pressure $(\geq 130 / 85 \mathrm{mmHg})$, elevated triglycerides $(\geq 1.7 \mathrm{mmol} / \mathrm{l})$, reduced high-density lipoprotein cholesterol $(<1.3 \mathrm{mmol} / \mathrm{l}$ in women and $<0.9 \mathrm{mmol} / \mathrm{l}$ in men) and elevated fasting glucose concentration ( $\geq 5.6 \mathrm{mmol} / \mathrm{l})(14)$.

Lifestyle was assessed by analyzing the prevalence of four behavioural patterns: nonsmoking, adequate fruit and vegetable consumption, healthy weight and satisfactory leisure time physical activity (LTPA). Except for anthropometrical measurements, the analysis of other lifestyle characteristics was based on selfreported data.

People who had never smoked and ex-smokers were included to the group of non-smokers.

Healthy weight was defined as a body mass index (BMI), calculated as weight in kilograms divided by square of height in meters, between 18,5 and $25 \mathrm{~kg} / \mathrm{m}^{2}(15)$.

While assessing eating habits two kinds of questionnaires were used: food frequency questionnaire and last 24-hour food questionnaire. Adequate fruit and vegetable consumption was defined as eating at least 5 portions of these products per day (16).

In the assessment of leisure-time physical activity people were asked whether they regularly practiced any physical activities (walking, jogging, swimming, bicycling etc) accumulating at least 30 minutes per session. Those who did were asked to recall the frequency of such activities. Satisfactory LTPA was defined as performing physical exercises for at least 30 minutes on most days of week (17).

Each participant of the study was given 1 or 0 points for each of the four mentioned behaviours ( 1 point for the presence and 0 points for the absence of the analyzed behaviour). The four mentioned behaviours were summed to create a lifestyle index which could range from 0 (no healthy behaviours) to 4 (all four healthy behaviours). Similar lifestyle assessments have already been used in the large-scale surveys by other authors $(18,19)$.

In order to compare the frequency and assess statistical significance of the given categories of quantitative characteristics in the analyzed groups the $\chi^{2}$ test was implemented. To identify factors that can contribute to metabolic risk, the logistic regression analysis was performed. Multivariate adjusted odd ratios (OR) with 95\% Confidence Interval (CI) stratified by gender were reported. All $p$-values were two-sided and $p<0.05$ was set as statistically significant. The statistical analysis was performed with the STATGRAPHICS Plus 5.1 programme.

Table 1. Demographic and lifestyle profile of study population

\begin{tabular}{|l|c|c|}
\hline Sociodemographic variable & $\mathbf{n}$ & $\%$ \\
\hline Sex & & \\
momen & 624 & 52.6 \\
\hline Age (years) & 563 & 47.4 \\
$20-34$ & 327 & \\
$35-64$ & 694 & 27.5 \\
$\geq 65$ & 166 & 58.5 \\
\hline Education & & 14.0 \\
elementary & 258 & \\
secondary & 764 & 21.7 \\
university & 165 & 64.4 \\
\hline Place of residence & & 13.9 \\
rural area & 347 & 29.2 \\
small town & 343 & 28.9 \\
large urban & 307 & 25.9 \\
capital city & 190 & 16.0 \\
\hline
\end{tabular}

\section{RESULTS}

Descriptive statistics on the study sample and healthy behaviours are displayed in Tables 1 and 2 . About $70.8 \%$ of all adults, significantly more women, declared not smoking which showed strong positive trends with increasing age and education. Adequate fruit and vegetables consumption declared $57.8 \%$ of respondents with significantly lower prevalence among seniors and largest urban agglomerations. Only $43.3 \%$ of adults had healthy weight which was more common among women and showed strong inverse trend with age and positive trend with education. Satisfactory LTPA was undertaken by $35.4 \%$, significantly less prevalent in seniors, higher educated and residents of the largest cities.

The lifestyle index was distributed as follows: $9.1 \%$ of the population did not meet any of the 4 recommendations while $35 \%, 38 \%$ and $14 \%$ met one, two and three recommendations, respectively. Only $3.01 \%$ of the whole population met all four recommendations which showed strong inverse trend with age and size of agglomeration and positive trend with education.

There are 16 possible unique combinations of the 4 analysed lifestyle characteristics. Only 2 of the lifestyle patterns were followed by more than $10 \%$ of the population and the most prevalent pattern was non-smoking with no adherence to any other healthy factor $(16.5 \%)$.

Metabolic syndrome was found in $19.7 \%$ of women and $18.1 \%$ of men. Relative risk of metabolic syndrome according to sociodemographic variables is presented in Table 3. Young adults $(\mathrm{OR}=0.14 \mathrm{in}$ men; $\mathrm{OR}=0.05$ in women $)$ and residents of rural areas $(\mathrm{OR}=0.53$ in men; $\mathrm{OR}=0.79$ in women) were significantly less likely to have MS. Educational level importantly contributed to 
Table 2. Prevalence (\%) of healthy lifestyle behaviors in the studied population

\begin{tabular}{|c|c|c|c|c|c|}
\hline $\begin{array}{l}\text { Sociodemographic } \\
\text { variable }\end{array}$ & Non-smoking & $\begin{array}{l}\text { Healthy } \\
\text { weight }^{b}\end{array}$ & $\begin{array}{l}\text { Fruits and } \\
\text { vegetables }^{c}\end{array}$ & $\begin{array}{l}\text { Regular } \\
\text { LTPA }^{d}\end{array}$ & $\begin{array}{l}\text { Lifestyle } \\
\text { Index }=4\end{array}$ \\
\hline \multicolumn{6}{|l|}{ Sex } \\
\hline women & 80.9 & 48.1 & 57.4 & 37.7 & 3.9 \\
\hline men & 60.6 & 38.5 & 58.2 & 33.3 & 2.1 \\
\hline \multicolumn{6}{|l|}{ Age (years) } \\
\hline $20-34$ & 64.8 & 72.3 & 59.7 & 34.9 & 5.0 \\
\hline $35-64$ & 62.8 & 34.7 & 62.1 & 43.8 & 2.2 \\
\hline$\geq 65$ & 85.4 & 22.9 & 51.6 & 27.8 & 1.8 \\
\hline \multicolumn{6}{|l|}{ Education } \\
\hline elementary & 63.2 & 30.9 & 57.1 & 39.8 & 1.7 \\
\hline secondary & 70.2 & 42.1 & 56.2 & 36.4 & 3.1 \\
\hline university & 78.9 & 56.9 & 60.1 & 30.3 & 4.2 \\
\hline \multicolumn{6}{|l|}{ Place of residence } \\
\hline rural area & 70.5 & 46.8 & 63.3 & 45.9 & 5.4 \\
\hline small town & 67.6 & 41.6 & 62.9 & 41.7 & 3.8 \\
\hline large urban & 68.9 & 43.3 & 55.9 & 37.9 & 1.8 \\
\hline capital city & 73.7 & 41.5 & 49.1 & 18.5 & 1.0 \\
\hline
\end{tabular}

Abbreviations: LTPA, leisure time physical activity.

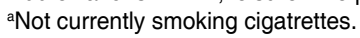

${ }^{\mathrm{b}} \mathrm{A}$ body mass index between 18.5 and $25 \mathrm{~kg} / \mathrm{m} 2$.

${ }^{\circ}$ Consuming 5 portions or more of fruits and vegetables per day.

d30 minutes or more of LTPA at least 5 times per week.

eMeeting all four recommendations: nonsmoking, healthy weight, adequate fruits and vegetables consumption and regular LTPA.

the metabolic risk in women, but not in men. Women with at least secondary education had significantly lower odds of MS relative to those with elementary education $(\mathrm{OR}=0.78$ for secondary; $\mathrm{OR}=0.72$ for university education).

Table 4 shows the contribution of single and multiple lifestyle behaviours to the metabolic risk. Regardless of age, education, place of residence and other lifestyle factors, the likelihood of MS was significantly lower in persons with healthy weight $(\mathrm{OR}=0.57$ for men; $\mathrm{OR}=0.59$ for women), consuming at least 5 portions of fruits or vegetables per day $(\mathrm{OR}=0.69$ for men; $\mathrm{OR}=0.72$ for women $)$ and with satisfactory LTPA (OR $=0.58$ for men; $\mathrm{OR}=0.55$ for women). Non-smokers had significantly lower odds of having MS only among men $(\mathrm{OR}=0.65 ; \mathrm{p}=0.047)$.

Significantly lower odds of MS were found in men engaged in at least 3 healthy lifestyle factors $(\mathrm{OR}=0.64 ; \mathrm{p}=0.043)$ while in women risk reduction is significant only while meeting all four criteria $(\mathrm{OR}=0.57, \mathrm{p}<0.05)$.

Table 3. Odd ratios (OR) and 95\% Confidence Interval (95\% Cl) of metabolic syndrome according to sociodemographic factors

\begin{tabular}{|l|c|c|c|c|}
\hline Sociodemographic factors & Women OR $(95 \%$ Cl) & p-value & Men OR (95\% Cl) & $p$-value \\
\hline Age (years) & & & & $p<0.001$ \\
$20-34$ & $0.05(0.02-0.14)$ & $p<0.001$ & $0.14(0.05-0.39)$ & $p>0.05$ \\
$35-64$ & $0.59(0.36-0.97)$ & $p<0.05$ & $0.91(0.63-2.11)$ & 1.00 \\
$\geq 65$ & 1.00 & & & $p>0.05$ \\
\hline Education & & & 1.00 & $p>0.05$ \\
elementary & 1.00 & $p<0.05$ & $0.85(0.5-1.43)$ & \\
secondary & $0.78(0.52-0.89)$ & $p<0.05$ & $0.82(0.38-1.76)$ & $p<0.05$ \\
university & $0.72(0.21-0.51)$ & & & $p<0.05$ \\
\hline Place of residence & & & $0.63(0.40-0.97)$ & $p<0.05$ \\
rural area & $0.79(0.54-0.99)$ & $p<0.05$ & $0.96(0.78-2.07)$ & $0.97(0.76-2.08)$ \\
small town & $0.95(0.65-1.63)$ & $p>0.05$ & 1.00 & \\
large urban & $0.97(0.66-1.65)$ & $p>0.05$ & & \\
capital city & 1.00 & & & \\
\hline
\end{tabular}


Table 4. Odd ratios (OR) and 95\% Confidence Interval (95\% CI) of metabolic syndrome according to healthy lifestyle factors

\begin{tabular}{|c|c|c|c|c|}
\hline Healthy lifestyle factors & Women OR (95\% Cl) & $p$-value & Men OR $(95 \% \mathrm{Cl})$ & $\mathrm{p}$-value \\
\hline $\begin{array}{l}\text { Non-smoking } \\
\text { yes } \\
\text { no }\end{array}$ & $\begin{array}{c}0.74(0.44-1.26) \\
1.00\end{array}$ & $p>0.05$ & $\begin{array}{c}0.65(0.41-0.99) \\
1.00\end{array}$ & $p<0.05$ \\
\hline $\begin{array}{l}\text { Healthy weight } \\
\text { yes } \\
\text { no }\end{array}$ & $\begin{array}{c}0.59(0.19-0.89) \\
1.00\end{array}$ & $p<0.05$ & $\begin{array}{c}0.57(0.17-0.78) \\
1.00\end{array}$ & $p<0.05$ \\
\hline $\begin{array}{l}\text { Fruits/vegetables } \\
\text { yes } \\
\text { no }\end{array}$ & $\begin{array}{c}0.72(0.65-0.99) \\
1.00\end{array}$ & $p<0.05$ & $\begin{array}{c}0.69(0.67-0.98) \\
1.00\end{array}$ & $p<0.05$ \\
\hline $\begin{array}{l}\text { Regular LTPA } \\
\text { yes } \\
\text { no }\end{array}$ & $\begin{array}{c}0.58(0.25-0.98) \\
1.00\end{array}$ & $p<0.05$ & $\begin{array}{c}0.55(0.17-0.97) \\
1.00\end{array}$ & $p<0.05$ \\
\hline $\begin{array}{l}\text { Lifestyle index } \\
\qquad \begin{array}{l}0 \\
1 \\
2 \\
3 \\
4\end{array}\end{array}$ & $\begin{array}{c}1.00 \\
0.97(0.56-2.72) \\
0.86(0.58-2.62) \\
0.81(0.46-0.99) \\
0.57(0.34-0.79)\end{array}$ & $\begin{array}{l}p>0.05 \\
p>0.05 \\
p>0.05 \\
p>0.05\end{array}$ & $\begin{array}{c}1.00 \\
0.99(0.41-2.41) \\
0.81(0.38-1.72) \\
0.64(0.62-1.49) \\
0.52(0.62-0.92)\end{array}$ & $\begin{array}{l}p>0.05 \\
p>0.05 \\
p>0.05 \\
p>0.05\end{array}$ \\
\hline
\end{tabular}

\section{DISCUSSION}

The main findings of this study include observation that the risk of metabolic syndrome is strongly associated not only with sociodemographic and particular healthy behaviours, but also with the patterns of lifestyle including not smoking, adequate fruit and vegetable consumption, healthy weight and regular physical activity. The results generated from this representative sample of Polish adults illustrate the extraordinarily low prevalence of healthy lifestyles as only $3.01 \%$ of the studied population followed a combination of a comprehensive set of the four behaviours. These results are similar to the findings of several other studies, including analyses of Reeves et al., Ford et al., Berrigan et al. where the overall prevalence of healthy lifestyle ranged from $3 \%$ to $6.8 \%(18,19,20)$.

Such a poor adherence to recommended guidelines is also a function of the prevalences of each lifestyle characteristics. Except for not smoking no other factor was prevalent in more than $58 \%$ of the population. As a result the prevalence of MS in the studied population is relatively high, especially when compared with other European or Canadian statistics $(7,21)$. However, direct comparisons in the prevalence of metabolic syndrome between various studies are difficult due to different definition of MS. However, when we used also the World Health Organization definition for the studied population, we found similar prevalence for the entire group without any substantial differences in the population subgroups.

Age, education and place of residence significantly influenced the metabolic risk. Young adults aged 20-34 years, persons with higher education, residents of rural areas were significantly less likely to have MS. The most probable explanation of this correlation can be huge differences in the prevalence of healthy weight between young adults and seniors, a significantly higher prevalence of not smoking and healthy weight among persons with university education and adequate consumption of fruits and vegetables and regular physical activity among residents of rural areas. These findings corroborate the results from the previous study of our Department as well as other authors reports indicating that age and education are among the strongest factors influencing metabolic risk or healthy behaviours $(8,11,22$, 23). As far as the place of residence is concerned, the analysis of the national results of the WOBASZ Project has already shown similar relationship between the prevalence of MS and the level of urbanization. According to these data, the metabolic syndrome is much less common in less urbanized areas of Poland, especially in the Eastern and South-Eastern part of the country (24).

The only healthy lifestyle factor which did not lower the chance of having metabolic syndrome in the present study was not smoking among women. Among men the correlation was significant, but with the p-value $=0.047$. Most, but not all studies (9), reported significantly higher risk of MS in current smokers $(8,10,25)$. The most probable explanation of this finding is the fact that the prevalence of abdominal obesity was significantly higher in not smoking than smoking women $(41.8 \%$ vs $21.6 \%, \mathrm{p}<0.001)$.

The results of this study confirm the reports of other authors about protective role of proper diet and physical activity in the development of metabolic syndrome $(9,21,26)$. However, direct comparisons between various studies concerning influence of eating habits on the MS risk are difficult due to different variables included in diet assessments. In the present analysis fruit and vegetable consumption was included into the lifestyle index, because of its public health importance. Additionally, body mass index was used in assessing lifestyle, because this measure reflects, in part, various dietary habits (fat, calories or, carbohydrates intake) and 
physical activity level. In spite of some findings about protective role of moderate alcohol consumption in the development of MS (27), this factor was not included into the lifestyle index because of the difficulty in elaborating reasonable and safe recommendations for the public.

According to the assessment of lifestyle patterns, important reduction of the risk of MS can be achieved only by meeting all four healthy lifestyle recommendations. Detailed analysis of the 16 possible lifestyle combinations revealed that higher prevalence of healthy weight and regular physical activity, singly or in combination, could provide additional $24.2 \%$ of people following all four healthy lifestyle factors. It is, therefore, highly probable that interventions designed to increase physical activity level and weight reduction have the potential to effectively reduce the metabolic risk of the enrolled population.

Based on the obtained results, it seems reasonable to elaborate effective messages about healthy lifestyles strictly for certain high-risk sociodemographic groups, like seniors, persons with lower educational attainment, residents of large urban areas. According to recent findings of Wannamethee et al., modification of lifestyle factors, even later in life, has considerable potential for primary prevention of the MS (10). Seniors could be reached with messages about healthy lifestyle in the context of self-management of chronic conditions.

Since abdominal obesity is the most prevalent element of MS in this population (38\% among women and $24 \%$ among men), it should become a priority to improve health promotion programmes focused on weight reduction, especially in women, persons over 65 years old and individuals with lower education. Special attention should be paid to elaborate effective message concerning proper dietary patterns and active lifestyle during and after smoking cessation period as about $20 \%$ of obese persons in this analysis were ex-smokers. Residents of large cities should be encouraged to increase their physical activity level and higher intake of fruit and vegetables.

Some study limitations need to be emphasized. The crosssectional nature of the analysis does not allow to investigate possible mechanisms of shown relationships between sociodemographic and lifestyle factors and the risk of metabolic syndrome. Well-known limitation is also the possibility of recall bias due to self-reported data on smoking, nutrition and physical activity level. Including only fruits and vegetables consumption and BMI into the lifestyle index (as a measure of dietary patterns) may not reflect nutritional habits with enough accuracy. Moreover combining all 4 lifestyle characteristics into a single indicator could be thought too strict as the prevalence of such combination of recommendations represents a very rare pattern of behavioral factors. It seems probably not achievable on the population scale and unlikely to change in response to public health interventions. However, such an index can be a useful population-level indicator of healthy lifestyle behaviors in long-term observation. Lifestyle index could be also helpful in counseling individual patients about healthier lifestyles. Finally, some authors currently expressed criticism on the use of the MS concept in the clinical evaluation of the patients. The most important argument against using it in practice is that the clustering of components of the MS is not accidental and occurs only in insulin-resistant persons. In the opinion of Reaven clinical emphasis should be on treating effectively and aggressively any risk factor that is present rather than labeling patients with the term metabolic syndrome (28). Another argument concerns the variability of definitions of MS created by various scientific associations which results in different findings. Taking into consideration all these opinions, the concept of MS still seems very useful as the goal of diagnosing the syndrome is to identify persons at increased risk of cardiovascular diseases. In clinical practice it can prompt a physician to look for and treat additional risk factors in patients with only one or two risk factors as well as help to persuade patients to change lifestyle or begin a long-term treatment before they develop overt diabetes mellitus or cardiovascular disease. Relationship between the presence of MS and morbidity as well as mortality rates has been well documented, even using different definitions of MS. Results from several studies including a large populationbased Italian study, the Framingham Offspring Study, the Botnia Study, the Kuopio Ischemic Heart Disease Study, the National Health and Nutrition Examination Survey II Mortality Study, the San Antonio Heart Study, and the DECODE study have shown that the presence of metabolic syndrome is associated with a significantly increased risk of total mortality and cardiovascular morbidity and mortality.

Despite the above limitations, these data indicate that metabolic syndrome of the studied population is in significant relation to sociodemographic and lifestyle behaviours. The study provides insight into prevalence and clustering of meeting recommendations for multiple healthy lifestyle factors and their contribution to metabolic risk. It also provides opportunity to compare lifestyle of developed western societies with health behaviours of residents of Poland - post-communist country during political and economic transformation. High response rate in this randomised, representative study increases generalizability of the results.

The obtained results demonstrate the challenges for healthcare and support the need for implementing effective interventions in the society, especially in the area of weight reduction and increasing physical activity level. Due to important differences in metabolic risk between various sociodemographic groups, health promotion interventions should be specific for the targeted subpopulations.

\section{Acknowledgements}

The Project was supported by the Polish Ministry of Health - Programme POLKARD 2003-2005.

\section{REFERENCES}

1. Mokdad AH, Marks JS, Stroup DF, Gerberding JL. Actual causes of death in the United States, 2000. JAMA. 2004 Mar 10;291(10):1238-45. Erratum in: JAMA. 2005 Jan 19;293(3):293-4. JAMA. 2005 Jan 19;293(3):298.

2. Murray CJ, Lopez AD. Mortality by cause for eight regions of the world: Global Burden of Disease Study. Lancet. 1997 May 3;349(9061):1269-76.

3. Drygas W, Kostka T, Jegier A, Kuński H. Long-term effects of different physical activity levels on coronary heart disease risk factors in middleaged men. Int J Sports Med. 2000 May;21(4):235-41.

4. Hu FB, Manson JE, Stampfer MJ, Colditz G, Liu S, Solomon CG, et al. Diet, lifestyle, and the risk of type 2 diabetes mellitus in women. N Engl J Med. 2001 Sep 13;345(11):790-7.

5. Stampfer MJ, Hu FB, Manson JE, Rimm EB, Willett WC. Primary prevention of coronary heart disease in women through diet and lifestyle. N Engl J Med. 2000 Jul 6;343(1):16-22.

6. Yusuf HR, Giles WH, Croft JB, Anda RF, Casper ML. Impact of multiple risk factor profiles on determining cardiovascular disease risk. Prev Med. 1998 Jan-Feb;27(1):1-9. 
7. Hu G, Qiao Q, Tuomilehto J, Balkau B, Borch-Johnsen K, Pyorala K; DECODE Study Group. Prevalence of the metabolic syndrome and its relation to all-cause and cardiovascular mortality in nondiabetic European men and women. Arch Intern Med. 2004 May 24;164(10):1066-76.

8. Park YW, Zhu S, Palaniappan L, Heshka S, Carnethon MR, Heymsfield SB. The metabolic syndrome: prevalence and associated risk factor findings in the US population from the Third National Health and Nutrition Examination Survey, 1988-1994. Arch Intern Med. 2003 Feb 24;163(4):427-36.

9. Villegas R, Creagh D, Hinchion R, O'Halloran D, Perry IJ. Prevalence and lifestyle determinants of the metabolic syndrome. Ir Med J. 2004 Nov-Dec;97(10):300-3.

10. Wannamethee SG, Shaper AG, Whincup PH. Modifiable lifestyle factors and the metabolic syndrome in older men: effects of lifestyle changes. J Am Geriatr Soc. 2006 Dec;54(12):1909-14.

11. Stelmach W, Kaczmarczyk-Chałas K, Bielecki W, Drygas W. How education, income, control over life and lifestyle contribute to risk factors for cardiovascular disease among adults in a post-communist country. Public Health. 2005 Jun;119(6):498-508.

12. Broda G, Rywik S. Multi-Center all-Polish Health Survey-WOBASZ Project. Defining the problem and aims of the study. Pol Popul Rev. 2005;27:29-36.

13. Rywik S, Kupść W, Piotrowski W, Broda G. Multi-Center all-Polish Health Survey - WOBASZ Project. Methodological assumption and logistics. Pol Popul Rev. 2005;27:37-50.

14. Grundy SM, Cleeman JI, Daniels SR, Donato KA, Eckel RH, Franklin BA, et al; American Heart Association; National Heart, Lung, and Blood Institute. Diagnosis and management of the metabolic syndrome: an American Heart Association/National Heart, Lung and Blood Institute Scientific Statement. Circulation. 2005 Oct 25;112(17):2735-52.

15. National Heart, Lung and Blood Institute; National Institutes of Health of Diabetes and Digestive and Kidney Diseases. Clinical guidelines on the identification, evaluation, and treatment of overweight and obesity in adults: the evidence report. Bethesda: NHLBI Health Information Center; 1998.

16. US Department of Health and Human Services [homepage on the Internet]. National Cancer Institute's 5-A-Day Program [cited 2004 Jun 8]. Available from: http://www.5aday.gov.

17. US Department of Health and Human Services. Physical activity and health: a report of the Surgeon General. Atlanta: National Center for
Chronic Disease Prevention and Health Promotion; 1996

18. Ford ES, Ford MA, Will JC, Galuska DA, Ballew C. Achieving a healthy lifestyle among United States adults: a long way to go. Ethn Dis. 2001;11(2):224-31.

19. Reeves MJ, Rafferty AP. Healthy lifestyle characteristics among adults in the United States, 2000. Arch Intern Med. 2005 Apr 25;165(8):854-7.

20. Berrigan D, Dodd K, Troiano RP, Krebs-Smith SM, Barbash RB. Patterns of health behavior in U.S. adults. Prev Med. 2003 May;36(5):615-23.

21. Brien SE, Katzmarzyk PT. Physical activity and the metabolic syndrome in Canada. Appl Physiol Nutr Metab. 2006 Feb;31(1):40-7.

22. Pronk NP, Anderson LH, Crain AL, Martinson BC, O'Connor PJ, Sherwood NE, et al. Meeting recommendations for multiple healthy lifestyle factors. Prevalence, clustering, and predictors among adolescent, adult, and senior health plan members. Am J Prev Med. 2004 Aug;27(2 Suppl):25-33.

23. Fine LJ, Philogene GS, Gramling R, Coups EJ, Sinha S. Prevalence of multiple chronic disease risk factors. 2001 National Health Interview Survey. Am J Prev Med. 2004 Aug;27(2 Suppl):18-24.

24. Wyrzykowski B, Zdrojewski T, Sygnowska E, Biela U, Drygas W, Tykarski A, et al. Epidemiology of the metabolic syndrome in Poland. The results of the Multi-Center all-Polish Health Survey - WOBASZ Project. Pol Heart J. 2005; 63 Suppl 4:S641-4.

25. Zhu S, St-Onge MP, Heshka S, Heymsfield SB. Lifestyle behaviours associated with lower risk of having the metabolic syndrome. Metabolism. 2004 Nov;53(11):1503-11.

26. Li CL, Lin JD, Lee SJ, Tseng RF. Associations between the metabolic syndrome and its components, watching television and physical activity Public Health. 2007 Feb;121(2):83-91.

27. Freiberg MS, Cabral HJ, Heeren TC, Vasan RS, Curtis Ellison R; Third National Health and Nutrition Examination Survey. Alcohol consumption and the prevalence of Metabolic Syndrome in the US: a cross-sectional analysis of data from the Third National Health and Nutrition Examination Survey. Diabetes Care. 2004 Dec;27(12):2954-9.

28. Reaven GM. The metabolic syndrome: is the diagnosis necessary? Am J Clin Nutr. 2006 Jun;83(6):1237-47. Erratum in: Am J Clin Nutr. 2006 Nov;84(5):1253.

Received July 25, 2008 Accepted in revised form October 20, 2008 